\title{
Evaluation of relationship between microbial load and drug efficacy of Andrographis paniculata during storage
}

\author{
G. K handel wal ${ }^{1 *}$, A paraj ita Gupta ${ }^{1}$, Deepak Dwivedi ${ }^{2}$, G. Prasad $^{1}$ and D.K . M aheshwari ${ }^{1}$
}

${ }^{1}$ Department of Botany and Microbiology, Gurukula Kangri Vishwavidyalaya, Haridwar - 249404 (Uttarakhand), INDIA ${ }^{2}$ Department of Microbiology, Barkatullah University, Bhopal (Madhya Pradesh), INDIA

*Corresponding author. E-mail: gaurav_microbio@yahoo.com

Received:F ebruary 2, 2013; Revised received:M arch 25, 2013; Accepted: April 10, 2013

Abstract: Three different extracts of Andrographis paniculata obtained by using three different solvents i.e. acetone, ethanol and water, were used to find out correlation of antimicrobial potency of the drug among them and with storage period of six months. Antibacterial activities were assessed by well diffusion method against Escherichia coli, Pseudomonas aeruginosa, Klebsiella pneumoniae, Staphylococcus aureus, Bacillus subtilis, and Salmonella typhi and antifungal activity by food poisoning technique against $C$ andida albicans. No definite pattern of antimicrobial nature in acetone, ethanol and aqueous extract could be observed. Acetone extract showed maximum inhibitory $(18.3 \mathrm{~mm})$ effect among all extract in general. Ethanol extract could attain second position and aqueous extract failed to inhibit growth of any organism even at 100\% concentration. A declined trend of inhibitory effect of extract with increased number of storage days has been found showing a negative relation between inhibitory effect of the drug and storage duration. But positive correlation between inhibitory effect and concentration has been recorded. No inhibition was recorded against $\mathrm{E}$. coli by any of the extract Bacterial load in term of CFU/g was found tremendously enhanced with increase of storage period. Negative correlation between microbial load and drug efficacy had been established while positive correlation between microbial load and storage period had been recorded.

Keywords: Andrographis paniculata, Antimicrobial activity, Gram positive bacteria, Gram negative bacteria, Microbial contamination, Storage

\section{INTRODUCTION}

The plants have been used in the treatment of various human ailments since ancient times. The test plant material Andrographis paniculata, member of family Acanthaceae, is a medicinal plant commonly known as Kalmegh, is found in the plains of India, Pakistan, Sri Lanka, and West Indies. Kalmegh has been used in Ayurveda, Unani and Siddha systems of medicines from ancient times. Literature survey shows wide spectrum of pharmacological activities of kalmegh either in the form of powder, extracts or in its isolated compounds with minimum side effects (Niranjan et al., 2010). About 26 different formulations of this plant are mentioned in Ayurveda as a popular remedy for liver disorders, bowl complaints of children, colic pain, common cold and upper respiratory tract infections (Kulyal et al., 2010; Wen-Wan Chao and Lin, 2010). It is widely used as an antidote against poisons of snakes and insect, and as an antimalarial agent (Dua et al., 1999). It is beneficial in general debility, asthma, bronchitis, filariasis and in hepatitis during clinical studies (Kulyal et al., 2010). It has a broad range of pharmacological effects (Roy et al., 2010). The herb was reported to contain andrographolide, diterpinoids, flavonoids and polyphenols as the major bioactive components (Rao et al.,2004; Wen-Wan Chao and Lin, 2010; Roy et al., 2010). Andrographolide has been reported for its anti-cancer (Sheeja and Kuttan, 2007), anti HIV (Calabrese et al., 2000), Cardioprotective (Yoopan et al., 2007) and hepatoprotective (Trivedi et al., 2007) properties among others. Several products fortified with extract and isolated compounds have been launched in national and international markets of this plant, but still it requires more research work for drug development and techniques that can be applied to improve the quality of such herbal drugs.

Voluminous information regarding multi-drug resistant bacterial pathogens (MDR) are available and large number of earlier antibiotics are failed to control the pathogens at present, therefore innovation of new antibiotic from microbial world becomes necessary in regular way as well as also from other natural resources like drug plant world. These drug plants are serving as better alternative source of remedies.

Since the herbal drug products are plant origin and the chances of microbial contamination since standing crop to harvest, transportation, storage, manufacturing till packing cannot be ignored and these contaminants may deteriorate the quality of the drug on one hand and on 
the other hand some human pathogens may also be associated with product which may cause adverse effect on health rather healing.

No suitable guidelines have been made in Indian pharmacopoeia covering this more important factor. It is an urgent need to make suitable technologies for collecting, storing, manufacturing, packing etc which can maximum minimize the chances of microbial contamination and their multiplication. In view of these facts, it has been thought to study the microbial status of A. paniculata and inhibitory effect of extract of this drug plant against different test organism during storage. With broad spectrum, as most of the Ayurvedic formulations undergoes spoilage due to excessive microbial contamination present or may be added during processing and results in poor quality, lack of efficacy and some side effects. Considering the above facts and importance of kalmegh world wide, the present study was undertaken for the evaluation of the antimicrobial efficacy of A. paniculata during storage of Kalmegh in order to observe the impact of microbial deterioration.

\section{MATERIALS AND METHODS}

Plant material: A. paniculata plants were collected from Shree Prem Nagar Aashram Nursery, Haridwar, Uttarakhand, India. The plant was collected in sterilizes polypacks. Whole plant was washed thoroughly with sterilized distil water and shade dried. After proper drying, the plant as a whole was finely grinded in to powder in an electric blender. After grinding, the powdered plant material is packed in to sterilized polypacks and kept for storage under room temperature for a period of $03 \& 06$ months respectively and for further study at initial stage. Preparation of plant extract: The solvents used for the extraction procedure in the present study were acetone, ethanol and water. $125 \mathrm{~g}$ of dried plant powder was extracted using $500 \mathrm{ml}$ of the extraction solvents $(25 \% \mathrm{w} /$ v) for $24 \mathrm{hr}$ in a Soxhlet extractor and was then subjected to filtration through sterile filter paper (Whatmann no.1). Solution was evaporated to dryness under controlled temperature to get final volume of $125 \mathrm{ml}$. The final concentration of the extract was so that $1.0 \mathrm{ml}$ of extract solution represented 1.0g of powdered material (Barreto et al., 2002). The extract solution thus obtained was designated as $100 \%$. Rest of the three dilutions $(75 \%$, $50 \%$, and $25 \%$ ) of each extract was prepared by using sterile distilled water.

Test organisms: The extracts of A. paniculata were screened against a total of six pathogenic strains of bacteria and one fungal strain. All the microbial strains were obtained from IMTECH (Institute of Microbial Technology, Chandigarh). The strains used for testing the antimicrobial activity of A.paniculata include four Gram-negative bacteria (Escherichia coli MTCC 443,
Pseudomonas aeruginosa MTCC 424, K lebsiella pneumoniae MTCC 3384, and Salmonella typhi MTCC 3216) and two Gram-positive bacteria (Bacillus substilis MTCC 441 and Staphylococcus aureus MTCC 7443) and one fungi (Candida albicans MTCC 183). All the bacterial cultures were maintained on nutrient agar media slants at $4{ }^{\circ} \mathrm{C}$ with a subculture period of one month. The fungal culture was maintained on YEPDA (Yeast extract peptone dextrose agar) slant.

Evaluation of microbial load: All microbiological analyses were carried out in triplicate. The total bacterial count was determined by the serial dilution method with slight modifications. The bacteria were counted after $24 \mathrm{hrs}$ incubation at $37^{\circ} \mathrm{C}$. The total bacterial counts were calculated by multiplying the average number of colonies with dilution factor and reported as colony forming unit per gram (cfu/g) of sample (Khanzadi, 2012). A ntimicrobial assay: The agar well diffusion method was followed for the estimation of antimicrobial activity of A. paniculata extract (Roy et al., 2010). 100 $\mu$ l of standardized microbial stock suspension $\left(1 \times 10^{5} \mathrm{CFU} /\right.$ $\mathrm{ml}$ ) of $24 \mathrm{hrs}$ old culture of test organism was thoroughly mixed with molten nutrient agar medium and poured into sterile petri plates. Wells of $6 \mathrm{~mm}$ diameter were punched into the agar medium with the help of sterile borer and filled with $100 \mu \mathrm{l}$ of each of the extract concentration i.e. $100 \%, 75 \%, 50 \%$, and $25 \%$ respectively. All the solvents served as negative control. Antibiotic (Amikacin) was simultaneously used as positive control. Each sample was assayed in triplicate and the mean value was observed. The plates were then incubated overnight at $37^{\circ} \mathrm{C}$ for $24 \mathrm{hrs}$. After incubation, the diameter of the zones of inhibition were measured and tabulated for each test microorganism.

The in vitro antifungal activity of the A. paniculata extracts was done by the poisoned food technique The pour plate method was used to test the mycelial growth response of the selected fungi to the $A$. paniculata extracts. In PF technique, two ml of each of the extract concentration $(100 \%, 75 \%, 50 \%$ and $25 \%)$ or solvent (control) was mixed with the molten potato dextrose agar (PDA) (Barreto et al., 2002). The test fungi was inoculated with $6 \mathrm{~mm}$ mycelial plugs from 5 days old culture and the plates were incubated at $25^{\circ} \mathrm{C}$ for five days (or until the colony reached the edge of the plate). The size of the fungal colonies were obtained by measuring the distances from the central plug to the edge of the colony across the two lines drawn at right angles to each other. The percent inhibition of mycelial growth of the test fungus was calculated as follows:

$\mathrm{I}=\mathrm{C}-\mathrm{T} / \mathrm{C} \times 100$

Where, $\mathrm{I}=$ Percent of Inhibition, $\mathrm{C}=$ Diameter of the fungal colony in the control plate, $\mathrm{T}=$ Diameter of the fungal colony in the treated plate. 


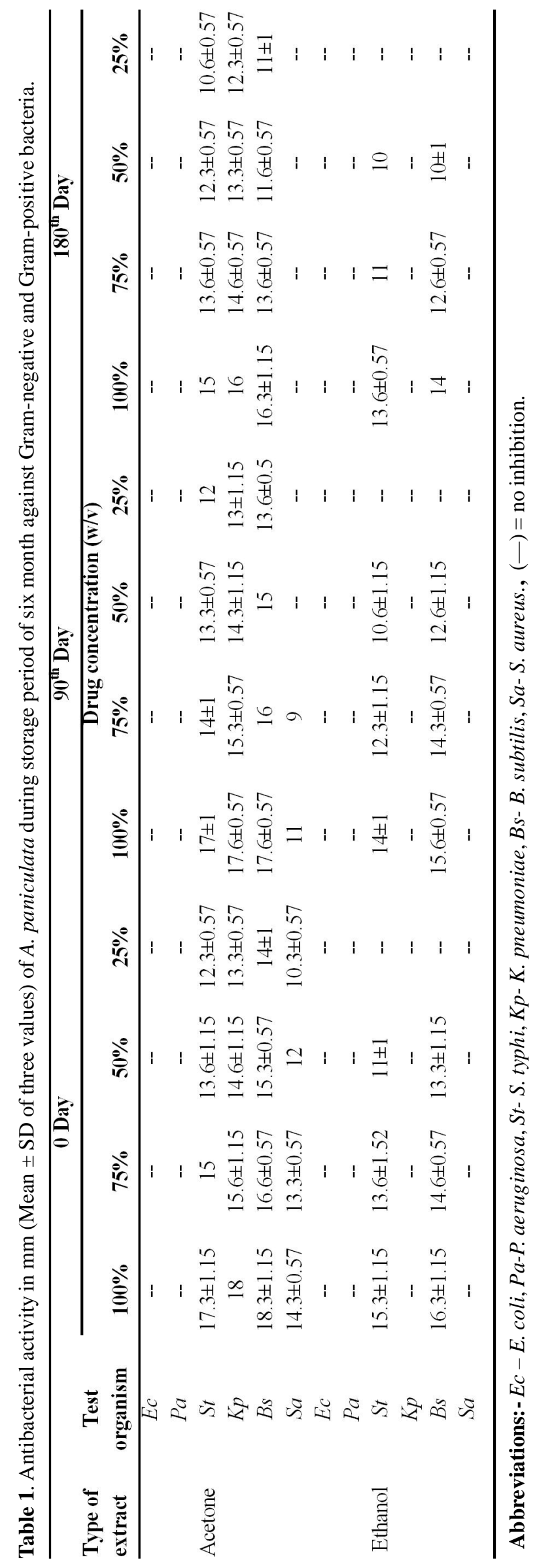

\section{RESULTS AND DISCUSSION}

The results of antibacterial activity of $A$. paniculata extracts (i.e. acetone, ethanol and aqueous) during storage period of drug for 6 months has been presented in Table 1 . The result of the present study showed that the two extract (acetone and ethanol) of A. paniculata showed antibacterial activities against $S$. typhi, $K$. pneumonia, B. subtilis and $S$. aureus. However, the potency of acetone extract at $100 \%$ was found promising when compared to that of standard antibiotic Amikacin (data not shown). Acetone extract at $100 \%$ concentration antibacterial result showed that diameter of inhibition zone ranging from 15 to $18.3 \mathrm{~mm}$, with the highest inhibition zone observed against $B$. subtilis $(18.3 \mathrm{~mm})$, followed by $\mathrm{K}$. pneumoniae $(16 \mathrm{~mm})$ and $\mathrm{S}$. typhi $(15 \mathrm{~mm})$. Out of 6 pathogens tested, 4 strains were found sensitive to acetone extract and 2 were found sensitive to ethanol extract. Ethanol extract at $100 \%$ concentration showed the diameter of inhibition zone ranging from $12.6 \mathrm{~mm}$ to $16.3 \mathrm{~mm}$, with the highest inhibition zone observed against $B$. subtilis $(16.3 \mathrm{~mm})$ followed by $\mathrm{S}$. typhi $(12.6 \mathrm{~mm})$.

Maximum efficacy was recorded in $100 \%$ concentration in both acetone and ethanol extracts and minimum efficacy was recorded at $25 \%$ concentration of acetone extract and no activity was observed at $25 \%$ concentration of ethanol extract, where as aqueous extract was found to be ineffective from the initial stage. A gradual declined trend of efficacy in general from first day onward was observed during six months storage period of the drug (Table 1).

Comparative record of the data at beginning (zero day) of the acetone extract of A. paniculata at $100 \%$ concentration revealed maximum drug efficacy against B. subtilis $(18.3 \mathrm{~mm})$ followed by K . pneumoniae $(18 \mathrm{~mm})$ and S. typhi $(17.3 \mathrm{~mm})$ while ethanol extract at $100 \%$ concentration revealed maximum activity against $B$. subtilis $(16.3 \mathrm{~mm})$ followed by $\mathrm{S}$. typhi $(15.3 \mathrm{~mm})$ and no activity against $K$. pneumoniae (Table 1 ). Where as aqueous extract of $A$. paniculata showed no activity against any of the test pathogens at any of the four concentrations. Absence of antibacterial activity in aqueous extract may be due to insolubility of the phytochemicals in water which may be essential for inhibition of the test organisms. Same trend was observed at $75 \%$, and $50 \%$, but $25 \%$ concentration of ethanol extract showed no activity against any of the test organisms as compared to the acetone extract which showed maximum activity of $14 \mathrm{~mm}$ at $25 \%$ against $B$. subtilis followed by K . pneumoniae $(13.3 \mathrm{~mm})$ and $\mathrm{S}$. typhi (12.3 $\mathrm{mm})$ (Table 1).

Similar trend was recorded during different interval of storage period i.e. 03 months and 06 months. However, a declined trend of potency was recorded in all the extract but the trend was some similar to zero day. Comparative observation among acetone and ethanol extract indicates 
Table 2. Anticandidal activity of A. paniculata during storage period of six month.

\begin{tabular}{ccccc}
\hline \multirow{2}{*}{ Extracting solvent } & $\begin{array}{c}\text { Drug concentration } \\
(\mathrm{w} / \mathrm{v})\end{array}$ & O Day & $90^{\text {tn }}$ Day & $180^{\text {th }}$ Day \\
\cline { 3 - 5 } & $100 \%$ & $90.7 \pm 0.86$ & $86.8 \pm 1.55$ & $80.7 \pm 0.92$ \\
Acetone & $75 \%$ & $87.6 \pm 02.33$ & $84.1 \pm 2.34$ & $76.1 \pm 0.86$ \\
& $50 \%$ & $85.7 \pm 0.92$ & 82.6 & $71.8 \pm 2.34$ \\
& $25 \%$ & $78.4 \pm 1.55$ & $70.7 \pm 0.86$ & $56.8 \pm 0.92$ \\
Ethanol & $100 \%$ & $88.8 \pm 0.86$ & 82.6 & $75.7 \pm 1.78$ \\
& $75 \%$ & $83.0 \pm 2.33$ & $76.4 \pm 0.92$ & $70.5 \pm 0.86$ \\
& $50 \%$ & $73.7 \pm 1.55$ & $66.8 \pm 1.55$ & 63 \\
& $25 \%$ & $65.6 \pm 0.86$ & $57.9 \pm 3.05$ & $52.5 \pm 1.78$ \\
\hline
\end{tabular}

that superior inhibitory nature in acetone extract may be due to more number/quantity of solubility of phytochemicals in used acetone solvent than ethanol. In general, acetone extract of this plant showed better results in term of inhibition than ethanol extract. Similar findings also have been recorded by Sharma et al. (2009). They studied the antibacterial activity of acetone and ethanol extract of $A$. paniculata against E. coli, P. mirabilis, K. pneumoniae, E. cloacae, P. aeruginosa, K. oxytoca and P. pseudomallei. Antibacterial potency of drug plants has been studied against certain organism by many researchers and found similar findings (Prasad et al., 2007; Roy et al., 2010; Radha et al., 2011).

The anticandidal activity of different extracts (i.e. acetone, ethanol and aqueous) of A. paniculata is present in Table 2. Anticandidal activity is reported by the growth inhibition percentage. With the exception of aqueous extract, both the extracts (acetone and ethanol) showed significant percentage of inhibition. When the two extracts were compared with each other, the acetone extract was found to have greater potential than ethanol extract. The percentage of inhibition continuously decreased with increase in storage period. For the two extracts the activity was found to be concentration dependent i.e. reduction of anticandidal activity with the dilution of plant extract. Maximum growth inhibition of fungal mycelia was recorded at $100 \%$ concentration of both the extracts since beginning (zero day) to till 180 day and minimum at $25 \%$ concentration respectively. The percentage of inhibition decreases with increase in dilution of the extracts as well as storage period of the plant material.

The acetone extract of $A$. paniculata at $100 \%$ concentration showed maximum inhibition of $90.7 \%$ at $100 \%$ concentration on zero day, $86.8 \%$ on $90^{\text {th }}$ day and $80.7 \%$ on $180^{\text {th }}$ day. With the dilution of the extract from $100 \%$ to $25 \%$, the inhibition percentage decreases to a minimum of $78.4 \%$ on $1^{\text {st }}$ day, $70.7 \%$ on $90^{\text {th }}$ day and $56.8 \%$ on $180^{\text {th }}$ day. Similar trend was observed with ethanol extract of A. paniculata, which showed maximum inhibition of $88.8 \%$ at $100 \%$ concentration on zero day, $82.6 \%$ on $90^{\text {th }}$ day and $75.7 \%$ on $180^{\text {th }}$ day. The $25 \%$ concentration of ethanol extract showed maximum inhibition of $65.6 \%$ on zero day, $57.9 \%$ on $90^{\text {th }}$ day and $52.5 \%$ on $180^{\text {th }}$ day. However, the aqueous extract of $A$ paniculata was found ineffective through out the study. When both the extracts (i.e. acetone and ethanol) were compared with each other, the acetone extract at all the

Table 3. Total bacterial count (TBC) in terms of CFU/g of A. paniculata during storage period of six months.

\begin{tabular}{|c|c|c|c|c|c|c|}
\hline \multirow{3}{*}{ Test plant } & \multirow{3}{*}{ Storage duration } & \multirow{3}{*}{ Dilution } & \multicolumn{4}{|c|}{ Total bacterial count (CFU/g)* } \\
\hline & & & \multicolumn{2}{|c|}{ Raw drug material } & \multicolumn{2}{|c|}{ Powder ed drug material } \\
\hline & & & Average value & Total count & Average value & Total count \\
\hline \multirow{3}{*}{ A.paniculata } & 0 day & $10^{4}$ & 44 & $44 \times 10^{4}$ & 36 & $36 \times 10^{4}$ \\
\hline & 90 day & $10^{4}$ & 77 & $77 \times 10^{4}$ & 60 & $60 \times 10^{4}$ \\
\hline & 180 day & $10^{4}$ & 157 & $157 \times 10^{4}$ & 115 & $115 \times 10^{4}$ \\
\hline
\end{tabular}

*Data shown as Total bacterial count (CFU/g) is calculated by multiplying the average number of colonies with dilution factor and reported as colony forming unit per gram of sample. 
concentration was found more effective from the zero day till $180^{\text {th }}$ day (Table 2 ).

The antifungal agent candid-B showed complete growth inhibition (100\%) against C.albicans (data not shown). The data revealed that the anti-candidal activity of both the extracts (i.e. acetone and ethanol) of A. paniculata was slightly lower than that of antifungal agent candidB. The infections of $\mathrm{C}$. albicans are more pronounced in the patients suffering from HIV infection. Candida albicans was commonly regarded as culture contaminant but now it is a major human pathogen due to the development of antimicrobial resistant (Caceres et al., 1991; Kieren et al., 1998; Michael and Pharm, 2001; Bonjar, 2004).

The present study revealed that highly diluted crude extracts of A. paniculata showed a significant antibacterial and antifungal activity even at lowest concentration leading to a strong possibility that these extracts may be applied for infections caused by $C$. albicans and other bacterial strains tested, but the present study focuses on the effect of storage on the antimicrobial activity which decreases with the storage of the plant material. A. paniculata is widely used medicinal plant with a number of medicinal applications. The biological activities of $A$. paniculata along with its active principles were briefly compiled by many researchers (Niranjan et al., 2010; Limsong et al., 2004; Singha et al ., 2003; Qureshi et al., 1997). Pursue of literature indicates that no such report has been documented till date in which negative correlation between microbial load and drug efficacy had been established with storage period.

The microbiological quality of $A$. paniculata for a storage period of six months is shown in table 3 . The plant samples (raw and grinded) showed elevated levels of contamination and were contaminated to varying degree with bacteria. The counts of total bacteria in the test plant materials increases with storage period. The total bacterial counts ranged from $44 \times 10^{4} \mathrm{CFU} / \mathrm{gms}$ in raw plant material and $36 \times 10^{4} \mathrm{CFU} / \mathrm{gms}$ in powdered material at zero day which increases up to $77 \times 10^{4} \mathrm{CFU} / \mathrm{gms}$ and $157 \times 10^{4} \mathrm{CFU} / \mathrm{gms}$ in raw plant material and $60 \times 10^{4} \mathrm{CFU} /$ gms and $118 \times 10^{4} \mathrm{CFU} / \mathrm{gms}$ in powdered material at $90^{\text {th }}$ day and $180^{\text {th }}$ day respectively. This is in agreement with the higher levels of aerobic bacteria found in other herbal materials reported earlier by other researchers (Wolfgang et al., 2001; Prasad et al., 2007; Oyetayo, 2008; Aneesh et al., 2009; Oluyege and Adelabu, 2010; Idu et al ., 2010; Khanzadi, 2012; Stevic et al., 2012) who dealt with the microflora of the medicinal plants.

The present findings showed that long term storage plays an important role as far as the quality of the herbal preparations is concerned and in agreement that contamination of herbal drugs by microorganisms not only cause bio deterioration but also reduce the efficacy of herbal drugs (Khurana et al., 2011). The toxins produced by microbes make herbal drugs unfit for human consumption because the contaminated drug may develop unwanted disease instead of disease being cured. A large number of reports regarding microbial contamination, adverse effects and allergic reactions (nausea, vomiting, diarrhea, respiratory tract infections, dizziness, weakness, and other serious disorders) associated with use of medicinal herbs and herbal preparations have been documented by many researchers (Paulsen et al., 1993; Bruynzeel, 1999; Ocasio et al., 1999; Varma et al., 2000; Elwin-Lewis, 2001 ).

Most of the plant extracts were considered to be broad spectrum antibacterial and antifungal agents and they may be considered for the development of more cheap medicines but the quality of these herbal extracts matters a lot. As our study revealed that the antimicrobial activity of A. paniculata extracts decreased continuously with increase in storage, raise questions regarding the quality of plant materials (raw and grinded) kept in the store houses for a long time.

\section{REFERENCES}

Aneesh, T.P., Hisham, M., Sonal, S.M., Manjusree, M., and Deepa, T.V. (2009). International market scenario of traditional Indian herbal drugs- India declining. International J ournal of G reen Pharmacy. 3(3):184-190.

Barreto, M., Critchely, A.T. and Straker, C.J. (2002). Extracts from seaweeds can promote fungal growth. J. Basic Microbiol., 42(5): 302-310.

Bonjar, G.H.S. (2004). Anti yeast activity of some plants used in traditional herbal medicine of Iran. J ournal of Biological Sciences. 4:212-215.

Bruynzeel, D.P. (1999). Contact dermatitis due to tea tree oil. Tropical M edicine and International Health. 4(9): 630.

Caceres, A., Lopez, B.R., Giron, M.A., Logemann, H. (1991). Plants used in Guatemala for the treatment of dermatophytic infections. 1. Screening for antimycotic activity of 44 plant extracts. J ournal of Ethanopharmacology. 31:263-276.

Calabrese, C., Berman, S.H., Babish, J.G., Ma. X., Shinto, L., Dorr, M., Wells, K., Wenner, G.A., and Standish, L.J. (2000). A phase I trial of andrographolide in HIV positive patients and normal volunteers. Phytother Res., 14:333-338.

Dua, V.K., Ojha, V.P., Biswas, S., Valecha, N., Singh, N., and Sharma, V.P. (1999). Antimalarial activity of different fractions isolated from the leaves of A. paniculata. J. Medicinal and Aromatic Plant Science. 21:1069-1073.

Elwin-Lewis, M. (2001). Should we be concerned about herbal remedies. J ournal of E thanopharmacol., 75: 141-164.

Idu, Mac-D., Solomon, E.O., Joseph, O.E., and Harret, M.E. (2010). Microbial load of some medicinal plants sold in some local markets in Abeokuta, Nigeria. Tropical J ournal of Pharmaceutical Research. 9(3): 251-256.

Khurana, N., Sharma, R.K., and Bhaduria, S. (2011). Microbiological quality assessment of some commericial herbal drugs. International J ournal of Pharmaceutical Quality Assurance. 3(4): 15-17.

Khanzadi, F.K. (2012). Microbiological quality assessment of 
commercially available medicinal plants in Peshawar city, Pakistan. Pak. J. B ot. 44(4): 1203-1208.

Kieren, A.M., Lyons, C.N., Rustad, T., Bowden, R.A., White, T.C. (1998). Rapid, transient flucanazole resistance in Candida albicans is associated with increased mRNA levels of CDR. Antimicrobial Agents and Chemotherapy. 42:25842589.

Kulyal, P., Tiwari, U.K., Shukla, A., and Gaur, A.K. (2010). Chemical constituents isolated from Andrographis paniculata. Indian J ournal of Chemi stry. 49B: 356-359.

Limsong, J., Benjavongkulchai, E., and Kuvatanasuchati, J. (2004). Inhibitory effect of some herbal extracts on adherence of Streptococcus mutans. J ournal of Ethnopharmacol., 92: 281-289.

Michael, E.K., and Pharm, D. (2001). Antifungal resistance among Candida species. Pharmacotherapy. 21:124-132.

Niranjan, A., Tewari, S.K., and Lehri, A. (2010). Biological activities of Kalmegh (Andr ographis paniculata Nees) and its active principles- A review. Indian J ournal of Natural Products and Resources. 1(2): 125-135.

Oyetayo, V.O. (2008). Microbial load and antimicrobial property of two Nigerian herbal remedies. Afr J Traditional, Compl and Altr M ed., 5(1): 74-78.

Ocasio, N.A., Salomowitz, B.H., Sher, M.R. (1999). Natural remedies recommended for the management of oral health. New York State Dental J ournal. 65: 22-24.

Oluyege, J.O., and Adelabu, D.M. (2010). Microbial contamination of some hawked herbal products in Ado-Ekiti, Nigeria. Continental. J. M icrobiology. 4(8): 8-14.

Paulsen, E., Andersen, K.E., Carlsen, L., Egsgaard, H. (1993). Carvone: an overlooked contact allergen cross-reacting with sesquiterpene lactones? Contact D ermatitis. 29: 138-143.

Prasad, G., Sharma, P., Gupta, K.K. and Chopra, A.K. (2007). Effect of microbial contaminants on Triphala drug efficacy during storage and enhancement of therapeutic spectrum of the drug In Vitro. H amdard M edicus. 50(1): 55-62.

Qureshi, S., Rai, M.K. and Agrawal, S.C. (1997). In vitro evaluation of inhibitory nature of extracts of 18 plant species of Chhindwara against 3-keratinophilic fungi. Hindustan Antibiol Bull. 39: 56-60.

Radha, R., Sermakkani, M. and Thangapandian, V. (2011). Evaluation of phytochemical and antimicrobial activity of
Andrographis paniculata nees (Acanthaceae) aerial parts. International J ournal of Pharmacy and Life Sciences. 2(2):562-567.

Rao, Y.K., Vimalamma, G., Rao, C.V., and Tzeng, Y. (2004). Flavonoids and andrographolides from Andrographis paniculata. Phytochemistry, 65:2317-2321.

Roy, S., Rao, K., Bhuvaneswari, Giri, A. and Mangamoori, L.N. (2010). Phytochemical analysis of Andrographis paniculata extract and its antimicrobial activity. World J Microbiol Biotechnol., 26: 85-91.

Sheeja, K. and Kuttan, G. (2007). Activation of cytotoxic T Lymphocyte response and attenuation of tumor growth in vivo by Andrographis paniculata extract and andrographolide. Immunopharmacol Immunotoxicol., 29:81-93.

Singha, P.K., Roy, S., and Dey, S. (2003). Antimicrobial activity of Andrographis paniculata. Fitoterapia. 74: 692-694.

Sharma, A., Verma, R., and Ramkete, P. (2009). Antibacterial activity of Medicinal Plants used by tribals against uti causing pathogens. World Applied Science J ournal. 7(3): 332339.

Stevic, T., Pavlovic, S., Stankovic, S., and Savikin, K. (2012). Pathogenic microorganism of medicinal herbal drugs. Arch. Biol. Sci. Belgrade., 64(1): 49-58.

Trivedi, N.P., Rawal, U.M. and Patel, B.P. (2007). Hepatoprotective effect of andrographolide against hexachlorocyclohexane induced oxidative injury. Integr Cancer Ther., 6:271-280.

Varma, S., Blackford, S., Statham, B.N. and Blackwell, A. (2000). Combined contact allergy to tea tree oil and lavender oil complicating chronic vulvovaginitis. C ontact D er matitis. 42: 309-310.

Wen-Wan Chao and Bi-Fong Lin. (2010). Isolation and identification of bioactive compounds in Andrographis paniculata (Chuanxinlian). Chinese M edicine. 5: 1-15.

Wolfgang, K., Erich, C. and Brigitte, K. (2001). Microbial contamination of medicinal plants- A review. Planta M edica. 68: 5-15.

Yoopan, N., Thisoda, P., Rangkadilok, N., Sahasitiwat, S., Pholphana, N., Ruchirawat, S., and Satayavivad, J. (2007). Cardiovascular effects of 14-deoxy-11, 12 didehydroandrographolide and Andrographis paniculata extracts. Planta Med., 73:503-511. 